\title{
1 Policy dialogue, surveillance and financial cooperation in East Asia
}

\author{
Gordon de Brouwer and Yunjong Wang
}

East Asia has a growing desire to strengthen its regional identity and forge effective and robust regional frameworks and institutions. This is the outcome of three main forces. One is the financial crises of 1997 and 1998, which revealed internal structural instabilities in some countries and the risk of relying too heavily on the uncertain goodwill of outsiders, notably the United States and the International Monetary Fund (IMF). Another is the internal economic and growth dynamic of East Asia, where intra-regional trade and investment and economic interdependence are rising. The third is the economic development and increasing openness of China, which represents an unprecedented opportunity to engage constructively and inclusively with a country that may be the world's next economic superpower.

Satisfying this desire is not an easy task. It requires change and commitment. If it is done on the cheap, the result will be insubstantial. Strong and effective financial governance is essential if strong and effective regional institutions are to be built. At this point in time, policy dialogue, surveillance and financial cooperation lie at the core of financial governance in East Asia.

The three elements are separate, but they build on each other. Policy dialogue refers to the framework by which policymakers from different countries come together to discuss issues. Surveillance is one set of issues by which policymakers not only share information and views on the events and problems of the day, but also can seek collegial advice, insights and support in dealing with domestic and international policy issues. Financial cooperation relates to the mechanisms by which countries can provide financial support to each other, regionally or globally, in the event of financial crisis. Financial cooperation is effective only if it is built on a solid foundation of policy dialogue and surveillance.

This volume brings together a range of expert views and assessments about the state of financial governance in East Asia and how this structure can be deepened and strengthened. We have grouped these views into four sets. The first presents some East Asian perspectives on the nature of policy dialogue and surveillance in the region. The second draws on the insights of other countries and regions in policy dialogue and surveillance. The third 


\section{Financial governance in East Asia}

looks at prospects for deeper financial cooperation in East Asia. The final set outlines a range of views on unilateral, regional and multilateral approaches to crisis prevention, minimisation and resolution.

\section{POLICY DIALOGUE AND SURVEILLANCE IN EAST ASIA}

The next two chapters in this volume examine a range of issues concerning official policy dialogue and surveillance on macroeconomic and financial issues in East Asia.

In 'Policy dialogue in East Asia: principles for success', Stephen Grenville looks at what East Asia can expect to gain from regional policy dialogue and how it can go about realising these gains. Much of the talk on improving policy dialogue in East Asia focuses on the gains from policy coordination. While not disparaging this, Grenville believes that one of the primary gains from regional policy dialogue is in fact the coalescing of common interests and views in the region and projecting these in global rules setting.

Grenville argues that there are three elements to this. First, behaviour within nation states is fairly highly regulated, even in market-based economies, but international cross-border activity is not. East Asia may be able to help fill in these regulatory gaps. Second, cross-border rules are set by other regional country groupings, notably Europe and the United States, with their interests in mind. East Asia should be a part of the rules setting process to ensure that its interests are protected and projected. Third, East Asia is poorly represented in many global institutions, and regional groupings may be a mechanism to address this 'democratic deficit'. Altogether, Grenville views regional and global policy dialogue and surveillance as complements.

Grenville sets out some desirable characteristics for regional groupings. The region should be comfortable with some overlap in policy groupings because it draws in different interested parties and helps build consensus. Groupings should be based on countries with common interests. If they are set up for the purpose of promoting frank conversations between policymakers, the number of participants is better kept to a manageable size. They also need the support of experts and a well-functioning physical secretariat to provide intellectual and logistical support. As a model, Grenville prefers the Bank for International Settlements over the IMF. He thinks that in the region the Manila Framework Group (MFG) and ASEAN+3 have the most potential as tools for effective surveillance, macroeconomic policy discussion, crisis management and reserves pooling, technical cooperation, and projecting the region's interests globally.

In Chapter 3, 'IMF and ADB perspectives on regional surveillance in East Asia', Gordon de Brouwer draws together views on regional surveillance expressed by IMF and Asian Development Bank (ADB) officials. Both the IMF and the ADB take surveillance seriously and have increased resources allocated to supporting it. Both institutions are deeply engaged in East Asian surveillance processes and have particular views on, and interests in, these processes. But they differ in aspects of emphasis. 
The IMF lives and breathes surveillance. As economies have become more complex and interdependent, the need to understand the links and limit the vulnerabilities that they create has become paramount. The IMF is actively involved in surveillance in many ways, and has sought to improve and expand surveillance over time. It puts primary emphasis on global surveillance mechanisms and, within the context of regional processes, on ensuring that the insights from experiences of all countries, including those from outside the region, are brought to help inform the regional debate. With respect to East Asia, the IMF sees a range of particular challenges in improving surveillance, including clearly defining the goals, focus and structure of regional surveillance, ensuring that global links are not weakened, and using the regional process to meet the region's own needs (rather than imitate the European process).

The ADB is more of a newcomer to surveillance and has set up an infrastructure to support regional surveillance, especially for the ASEAN and ASEAN +3 processes. It is more overtly committed to the notion of a regional financial architecture, including cooperative regional financing and exchange rate arrangements, in which it would like to have a core function. The ADB puts the emphasis on regional surveillance as a device to garner better ownership of policy dialogue and reform, and to balance global and outside assessments with well-articulated and sound regional views and assessments.

The IMF and ADB share common ground in terms of their commitment to robust and effective surveillance mechanisms, although they differ in their enthusiasm for regional processes. Both institutions have particular strengths: the IMF's is its unrivalled experience and frankness in policy analysis and surveillance; the ADB's is its strong on-the-ground presence in East Asia. But they also have weaknesses. The IMF is seen as too aloof from the region. It is seen as not active enough in East Asia, not particularly interested in regional institution building, and sometimes too arrogant in its manner. The ADB is seen as too adventurous. It is pushing the boundaries of its role as a regional development bank into a role of regional monetary fund, potentially diverting resources from its core function of supporting development in the whole Asia Pacific region. As a development bank, its policy remit does not cover the region's industrialised economies. And it is inadequately staffed for the job. This creates challenges for the two institutions themselves and for regional policymakers in how they might use them.

\section{INSIGHTS FROM OTHERS' EXPERIENCE WITH POLICY DIALOGUE AND SURVEILLANCE}

The search for viable mechanisms for policy dialogue, surveillance and financial cooperation are, of course, not isolated to East Asia. Many countries in other regions have been, and still are, grappling with the same sorts of issues and problems. The next three chapters in this volume draw on the experience of other countries and regions in setting up surveillance processes and structures to support regional economic and financial cooperation. 


\section{Financial governance in East Asia}

In Chapter 4, 'Structures to support stability and growth: some observations based on UK experience', Andrew Kilpatrick draws on insights from the UK Treasury to discuss how the United Kingdom has used the regional policy dialogue and surveillance processes of the European Union in the post-war period to support the domestic economy. He makes two basic points.

The first is that the only way to secure domestic economic stability and growth is to get the country's basic macroeconomic framework right. This means having flexible, transparent and market-based economic systems, supported by responsible and robust monetary, fiscal and financial frameworks. This is all the more important in the contemporary globalised domestic economy, where external shocks are relatively frequent, large, and quickly transmitted. Countries are responsible for themselves; the burden of making good policy lies at home.

Kilpatrick also sees a clear and important role for regional policy dialogue and surveillance in this process. Embedded in regional institutions for policy dialogue, rigorous multilateral surveillance can support domestic policymaking, and hence domestic stability and growth, by providing mechanisms for frank and useful discussion of economic issues and problems in a constructive and supportive environment, and by creating peer pressure for policymakers in less well-performing countries to pursue corrective stabilising policies.

Developing the sort of policy dialogue infrastructure that promotes effective surveillance is not an easy task. In the first place, it takes a lot of time. Kilpatrick highlights the many steps involved in creating, running and maintaining institutions for regional policy dialogue in Europe. The process started with cooperation in simple areas of common interest and progressed unevenly. On occasion, the steps were big, led by politicians with a vision for a united integrated Europe. At times, they were small, just holding ground or under enormous internal pressure (such as in 1992 when the European exchange rate mechanism fell apart); in these cases, the sheer inertia of the bureaucratic and institutional process helped keep regional cooperation going.

Policy dialogue in Europe proceeded on the basis of functional cooperation: from its genesis in the European Coal and Steel Community to the focus on regional monetary cooperation to reduce financial uncertainty. It is still present in the current structure of European policy dialogue, with special dialogue forums for pressing European macroeconomic issues, like the budgetary surveillance program built into the Stability and Growth Pact to deal with Europe's chronic tendency to fiscal deficits, the policy dialogue program built into the Employment Guidelines to deal with Europe's relatively inflexible labour markets, and the Cardiff process for economic reform to engineer a regional mechanism and constituency for domestic structural reform. The implication for East Asia of the success of functional policy dialogue in Europe is clear: institutions for policy dialogue should be created, and they should focus on the economic issues that are important to East Asia.

The next chapter, 'The complex political economy of cooperation and integration', draws on some insights from European experience more generally. 
Randy Henning uses the various models that political economists have used to explain European institution building to explain past and likely future cooperation and integration in East Asia. He critically assesses a range of theories of integration, including the role of the market and institutions in driving integration, cooperation in one area 'spilling over' to other areas, converging national political interests, and the pattern of global influence and control.

Henning reckons that East Asian integration looks relatively deep in terms of market interaction but is superficial in terms of institutions, particularly because these have been dominated by East Asian countries' bilateral relationships with the United States. As East Asia moves into more regionally oriented trade and investment integration, it is likely that this will spill over into deeper financial and monetary cooperation. National political interests are still very diverse in the region, but the financial crisis and the imperative of stable development in China and its integration into the world economy may be changing this.

Stability or otherwise in the global system - and particularly economic and political stability in the United States - can be a key driver of forces towards regional integration. Henning argues that, contrary to perceptions, a desire for political integration was not the primary driving force of economic integration in Europe. Systemic shocks, especially from the United States (including the collapse of Bretton Woods), were critical in the formation of a European currency union. It took repeated shocks over several decades to get Europe to focus on monetary integration at the regional level.

There was nothing inevitable in this. The integration of markets in goods and services and in capital and labour were important in constructing a foundation for monetary integration to take place. But it was how this basis was used, and how political support was garnered in response to global instability, that ultimately created a consensus for monetary union. Indeed, the consensus about conditions for entry and which countries would enter monetary union were only made at the last moment. For East Asia, the prospects for deeper monetary integration depend on two factors. The first is that the endogenous preconditions for integration - namely, that the region be deeply economically integrated by trade and investment - need to be sufficiently in place. The second is that global conditions are such that monetary integration is a feasible (and the 'right') response to systemic instability and imbalance.

In Chapter 6, 'A stocktake of institutions for regional cooperation', Takatoshi Ito and Koji Narita focus on possible frameworks to implement financial cooperation. These include surveillance, crisis financing, and monetary integration. To put discussion into perspective, they start with a look at multilateral organisations and forums and at how particular regions elsewhere in the world have approached regional cooperation. They provide substantial detail about European, Arab and Latin American policy dialogue and cooperation. They highlight that Europe has been the most successful of 


\section{Financial governance in East Asia}

these regions. But even there, progress in regional financial and monetary cooperation has been far from smooth and elements of cooperation have been subject occasionally to stress and collapse. Success has in large part been due to persistence by key parties involved.

Ito and Narita argue that deep integration in East Asia will require effective surveillance mechanisms as a first step. They reckon that one of the most successful surveillance processes is that of the Working Group 3 subgroup of the OECD's Economic Policy Committee, which holds a one-day private meeting four times a year attended by deputies from largely G-10 finance ministries and central banks. Discussions are chaired by the IMF, are detailed and frank, and cover key macroeconomic issues in industrialised and emerging market economies. The region would do well to try to emulate its success. Ito and Narita critically discuss experience with the MFG, APEC finance ministers meetings, ASEAN finance ministers meetings, ASEAN+3 finance ministers meetings and the Executives Meeting of East Asia and Pacific Central Banks (EMEAP). While the region has made some progress with surveillance, it can make further improvements.

Ito and Narita also look at financial cooperation processes. A similar story emerges with respect to financial cooperation. Europe again stands out as a region that has cooperated in an effective manner to manage systemic risks. East Asia has made some progress with the Chiang Mai Initiative (CMI) but it is only a first step forward.

The five chapters on policy dialogue and surveillance discussed above cover a lot of ground. The main follow-up issue that emerged in discussions on these papers was balancing the value of insights from Europe's experience with integration with the danger of seeing its path as the only one or 'the right one' for East Asia. Discussion focused on three elements of Europe's experience.

The first element is that integration in Europe has been supported by a long history of dialogue over a wide-ranging set of policy issues in a wideranging set of institutions. These policy issues have changed over time in response to the vicissitudes and problems of the day. The issues have ranged from the collapse of the gold standard, managing post-World War I reparations, post-World War II reconstruction, payments imbalances, different economic cycles, movement of capital, exchange rates, structural imbalances and rigidities, and financial market supervision. The institutions used as the vehicles for discussion have existed at political and bureaucratic levels, ranging from the Council of Economic and Finance Ministers and their myriad committees to the BIS and the European Commission. Maintaining strong bilateral relations have remained important in this process.

This system of institutions and meetings was flexible enough to bring new issues to the table and was robust enough to provide an apparatus to maintain dialogue and contact even when there had been political setbacks and major economic and financial disturbances. There was nothing automatic or necessary about the system's capacity to deliver this. Most crucially, it depended on 
policymakers being able to trust and respect each other and develop constructive working relationships. This could happen because key senior people were committed to a process of engagement and openness and the structures allowed the same people to stay in regular contact with each other over long periods in the formative years of European institution building.

Looking at the implications for East Asia, there was uniformity in discussions on policy dialogue that the region needs stronger frameworks and institutions for surveillance. There is wariness about the excessive legalism and formalism that seem characteristic of European integration, but there is a general view that regional policy dialogue needs a stronger institutional underpinning, such as a secretariat to provide logistical support and think-tanks to provide ideas and technocratic support. Sending the same senior people to meetings, having a regular, independent and authoritative chair, and using specialists to provide background material, could be useful in improving surveillance in East Asia. The rotation system that is characteristic of many East Asian bureaucracies - by which staff change positions every two years and have strong policy-process skills but weak specialist knowledge and connections - is a constraint on policymakers developing expertise and professional relationships with their counterparts.

The main challenge in strengthening dialogue and surveillance in East Asia is securing political commitment to engage in frank discussion about domestic policy issues and problems. This is more of a problem in some countries than in others. Some countries appear to be inclined to see discussion on economic and financial issues as a challenge to the domestic policymaking authorities and a form of interference in internal affairs. But hectoring and invasiveness are certainly not the intention of those in the region who advocate more substantive surveillance, as the papers in this volume show. As policymakers build up a set of constructive experiences with experiments in surveillance, East Asian policy dialogue and cooperation will, hopefully, develop and mature. Without widespread political commitment, regional surveillance and policy dialogue in East Asia will lack substance.

The second element discussed in relation to the European experience was that monetary integration in Europe was substantially influenced by that region's relationship with the United States. This was not just a reaction to the collapse of Bretton Woods and Europe's various experiences in dealing with external shocks in an environment of open capital markets, although events such as these had a profound impact since the common market had been predicated on the fixed exchange system underpinned by Bretton Woods and capital controls. It was also an attempt to give Europe a bigger voice in world affairs to advance its interests and balance those of the United States. There are loud echoes of this in post-crisis East Asia.

For East Asia, the rise of regionalism poses new challenges. East Asian regionalism is partly based on dissatisfaction with economic and financial instability in the world's major economies, especially due to big movements of the US dollar against the yen and euro. And it is partly based on deep 


\section{Financial governance in East Asia}

dissatisfaction with how the United States responded to the crisis and exercised its power. Europe responded to these sorts of issues by looking inwards, constructing external trade barriers and expensive schemes to protect segments of its economy and constraining the product and input markets, especially labour markets. This reduced the welfare gains to Europeans and outsiders. East Asia is in a position to respond more constructively than Europe. East Asia's interests are fundamentally global; a retreat to 'fortress Asia' would weaken economic growth, development, stability and welfare.

Europe also had the advantage of a clear economic leader in monetary management, Germany. East Asia does not. Japan is the region's biggest economy, but weak growth, deflation and a dysfunctional financial system also make it one of the region's more vulnerable economies. This means that the costs in achieving consensus about policy aims and frameworks are likely to be higher in Asia than Europe.

There is a desire to create an East Asian Community as a strong statement of the region's identity and a framework to project its interests. But what is East Asian? Is it just ASEAN+3? The East Asian region also includes Hong Kong and Taiwan, on the one hand, and Australia and New Zealand on the other. There is a strong argument that the first two of these economies are implicitly included because they are part of China, although they do not have a direct voice in dialogue and ideas-setting. Some more explicit form of inclusion would be valuable, especially in discussions on financial markets and institutions.

The second set of countries is sometimes referred to as a separate bloc, Oceania, but in fact these are developed economies which are highly integrated with the rest of East Asia. They are not big economies in the scheme of things, but excluding them is not a trivial issue. In the first place, including them in regional forums expands the set of developed economies with wellfunctioning economic and financial systems and markets. Including them also means that the East Asian community and identity are not defined by ethnicity ('no blue eyes, blond hair'). This matters strategically because it constrains the pursuit of regionalism as an exercise in demagogy and populism.

A third element discussed was whether European monetary integration remains unfinished business. People are inclined to see their point in time as the endpoint or even the culmination of history. It would be misleading to think that the status quo is forever. European monetary union is in the process of being expanded because of the expansion of the European Union to Eastern Europe. This represents a shift in the balance of power within Europe from big to small countries, and potentially a realignment from Western European dominance. Regimes do not last forever, as the history of exchange and monetary regimes and composition of regional blocs over the past century show. For East Asia, the point to keep in mind is that the endpoint of European monetary union is itself a moving feast. 


\section{FINANCIAL COOPERATION}

The next three chapters in this volume look at regional financial cooperation in East Asia for the prevention and resolution of financial crises. Two of these chapters set the context for regional financial cooperation, looking at the political economy and theoretical motivations for enhanced regional financial cooperation. The third chapter sets out possible instruments for cooperation and possible institutional vehicles to implement them.

In Chapter 7, 'Strengthening regional financial cooperation in East Asia', Haruhiko Kuroda and Masahiro Kawai discuss the need for stronger financial cooperation in East Asia. They believe that the 1997-98 financial crisis prompted East Asian economies to realise the potential benefits of having stronger cooperative institutions for crisis prevention, management and resolution. They argue that the regional financial architecture needs to be improved. They outline recent developments in financial cooperation in the region and examine possible directions for the future.

Kuroda and Kawai recommend that the regional surveillance process be made more effective. They canvass the option of creating a common pool of foreign exchange reserves to allow more flexible financial support at times of crises and contagion while minimising the problem of moral hazard. The arrangement must be consistent with the global framework. In particular, it must ensure private sector involvement for crisis management and resolution. They also argue that the choice about exchange rate regimes should be coordinated at the regional level, with a long-term vision of regional monetary integration. There is no presumption that the 'region' for financial cooperation is the same as the 'region' for monetary union.

In the next chapter, 'The management of financial crises: theory and policy', Prasanna Gai outlines an analytical framework for thinking about the relative benefits of international policy cooperation in dealing with financial crises. He starts at the general level, critically examining the theoretical literature on the causes and welfare effects of financial crises and ways to deal with them, including country clubs, swap arrangements, national liquidity management and payment standstills. He then sets out a useful and accessible model to analyse the incentives and tradeoffs in the design of sovereign debt contracts and the way the official sector can influence them. He shows that the benefits of a coherent crisis resolution framework are most likely to accrue if the official sector can identify the source of the financial problems and apply emergency financing effectively.

Gai's analysis highlights the importance of both effective monitoring, surveillance and policy dialogue and well-functioning institutions that perform or facilitate these functions. He discusses first the role of IMF programs in catalysing private finance. He argues that, to leverage private sector involvement effectively, official sector finance must improve the incentives of debtors to voluntarily engage in policy adjustment and willingly maintain 
credit lines to the crisis country. One element of this is tightly focused conditionality aligned to actual outcomes relevant to the financial problems at hand.

Gai also sees two implications for regional policy dialogue in East Asia. The first is that there is a potential role for greater regional dialogue and coordination with creditors. He suggests expanding the MFG to also act as a 'country club' for ensuring full communication between policymakers and private sector participants. Increased transparency is not a panacea against crisis, but it adds additional scrutiny and discipline which may bring significant welfare benefits. The second is that there is an underlying logic for developing an 'Asian Arrangements to Borrow' (AAB), as argued by Wang in the next chapter, because it brings additional firefighting power to crisis management, and home-country ownership of reform in such management.

In Chapter 9, 'Instruments and techniques for financial cooperation', Yunjong Wang opens up discussion of the various devices through which the region can deliver financial support. He sets the context by outlining the rationale for regional financial cooperation and critically assessing existing multilateral financial arrangements. He also appraises existing arrangements for support in East Asia, including the ASEAN swap arrangement and the network of bilateral swap arrangements set up under the CMI by the ASEAN +3 countries.

Wang canvasses a number of options for regional liquidity facilities beyond the CMI. These include an AAB and an Asian Monetary Fund. The proposals envisage multilateral cooperation, and so go beyond the NBSA, but they have different modalities. The AAB, modelled on the New Arrangements to Borrow, would allocate credit to countries on the basis of need, subject to an overall constraint set by benchmark economic criteria, a penalty rate of interest, and effective monitoring and surveillance. The AMF would be an institutional arrangement to pool and allocate funds to regional countries in crisis. There is concern about the costs associated with a large bureaucratic institution.

\section{UNILATERAL, REGIONAL AND GLOBAL RESPONSES TO CRISES}

The next four papers in this volume look at some of the issues about how countries might deal with financial crises: should they go it alone, should they seek regional support, or should they rely on global mechanisms?

In Chapter 10, 'The compatibility of capital controls with the development of financial markets', Menzie Chinn looks at one aspect of unilateral action by countries. Countries can impose capital controls to prevent or deal with a financial crisis. Chinn explores empirically whether capital controls affect a country's financial development. Financial development is important because it is expected to improve the efficiency of the allocation of financial resources and the monitoring of capital projects. Chinn investigates a substantially broader set of proxy measures of financial development than the standard measures, such as the volume of bank intermediation and an increasing role for equity capital. He also uses a variety of measures of capital controls, including the 
IMF's measures of exchange restrictions and Quinn's index of financial openness.

Chinn reports some interesting outcomes. The econometric results suggest that the rate of financial development, as measured by private credit creation and stock market activity, is negatively related to the existence of capital controls. However, the strength of this relationship varies with the empirical measure used and with the level of development. The negative relationship between capital controls and financial development is most robust with respect to the equity market. Equity market activity appears to be linked to capital controls in both the full sample and a restricted sample of developing countries. The results pertaining to equity market development are of particular importance, as recent work suggests that equity markets are more important than bank-directed finance for the transfer of new technology.

In Chapter 11, 'Unilateral, regional and multilateral options for East Asia', Ramkishen Rajan looks at the array of options available for policymakers to deal with financial crises. He starts by observing that in a world where policymakers face the risk of financial crises on the capital account of the balance of payments, countries also face the risk of contagion and so need to have an array of policy responses at hand. Because these crises present themselves as a shortage of liquidity, it is important that countries have sufficient access to liquidity to deal with them.

Countries can act unilaterally to safeguard against capital account crises, through capital controls and the accumulation of foreign exchange reserves. They can also use foreign banks and private contingent credit lines (CCLs). There are limitations associated with all these. For example, capital controls can affect investor confidence. The carry cost of large foreign exchange reserves can be substantial because the interest paid on domestic liabilities is typically greater than the interest received on foreign assets. And private CCLs are likely to be small and hard to actually use in a crisis. This is because the providers of the lines do not like them being used, and because financial institutions are likely to reduce exposures to the countries, or others like it, to minimise the risks created by the facility and the signal it gives that the country has problems (that is, dynamic hedging).

Rajan argues that there is a need for cooperation to deal with these risks. One solution has been the development of the IMF's CCL facility. Rajan argues that this is ineffective since the loss of control and sovereignty entailed in using the facility outweighs the gain from the option value of access to a CCL facility. Moreover, countries will not use the facility because to do so would signal weakness and may itself cause a loss of market confidence. Multilateral solutions might not be the best way to deal with contagion. Rather, given that contagion and spillovers tend to be regional rather than global, it might be better to design mechanisms at the regional level.

Rajan argues that regional arrangements may indeed be superior to multilateral arrangements because countries' vested interests in a regional 
facility might be higher, either in terms of the likelihood of them being used (because crises are regional) or because countries have closer ties and relations with other countries in the region. For these reasons, he supports a quickdispersing regional credit facility which would act basically as a lender of last resort in a financial crisis. It would act independently of the IMF, at least in the preliminary stages, so long as the crisis remains relatively small and localised.

Martin Parkinson, Phil Garton and Ian Dickson follow up analysis of some of these issues in Chapter 12, 'The role of regional financial arrangements in the international financial architecture'. They focus on some key issues and challenges that need to be considered in thinking about how regional arrangements might evolve.

They start by looking at the factors that have led to increased pressures on IMF resources, particularly in the past decade, and that have given rise to large-scale financing from sources outside the IMF in the midst of crises. The changing nature of balance of payments crises associated with increasing capital mobility, and the uncertainties surrounding the effectiveness of official financing, are crucial issues in constructing mechanisms and institutions for crisis financing.

Regional financing arrangements can relate to those provided by the IMF in different ways. One approach - which they call 'complementary financing' - involves both the IMF and a regional facility in an explicitly coordinated approach from the beginning of any crisis. Either the IMF or the regional facility could take the role as lead crisis manager, supplemented by funds from the other in either a first or second line of defence role (that is, funds that are either firmly or else provisionally dedicated by countries in support of an IMF package). Looking back on the experience in the East Asian crisis, Parkinson, Garton and Dickson judge that second lines of defence are ineffective and counterproductive; Ito and Narita reach the same conclusion in Chapter 6. Parkinson, Garton and Dickson also examine an alternative model - 'concentric lines of defence' - which entails the lead manager initially acting alone, with only implicit back-up from the 'lender of second resort' should the approach of the lead manager fail. Both models have supporters in East Asia, but the latter has garnered most attention.

While recognising the rationale for advocating a 'concentric lines of defence' approach, Parkinson, Garton and Dickson outline a number of challenges that need to be addressed to ensure that such proposal is feasible. The challenges include issues of appropriate crisis diagnosis; the relationship to current moves to develop effective mechanisms for private sector involvement (PSI); the credibility of lending conditions; and possible coordination failures if the IMF is the 'lender of second resort'.

In the final chapter in this volume, 'The Basel process and regional harmonisation in an Asian context', Shinichi Yoshikuni provides some insights into how the BIS sees the interactions between regional and global 
developments. He notes that the globalisation of financial markets has produced seemingly conflicting results. On the one hand, central banks and regulatory authorities have cooperated to come up with a set of standards to be applied globally, with the so-called Basel Process serving as one of the central vehicles. On the other hand, repeated episodes of financial crises with volatile market activities have led to calls for regional cooperation between such institutions. Yoshikuni suggests that there are two pressing issues.

The first issue is whether - and how - global standards can be reconciled with regional interests. Yoshikuni describes how regional sentiment in East Asia pressured the BIS to become less Europe-centric and to focus on developments in East Asia. He also argues that globalism and regionalism are not mutually incompatible, even if tensions exist at times. He says that they can be complementary forces that condition each other: sustainable globalism will bend to accommodate regional elements, and sustainable regionalism will be open enough to avoid insularity and loss of economic opportunity. In a fundamental sense, the dichotomy between global and regional interests is false.

The second issue - rethinking bank regulation - is whether it is possible to incorporate regional elements in the Basel Process, and indeed whether independent regional bodies are needed in addition to the Basel Process. Yoshikuni argues that regulatory harmonisation embedded in the Basel Process is a key element in the international regulatory infrastructure. This process has been influenced by market participants and regional developments. Moreover, globalisation - which creates new interdependencies between markets and institutions - has forced it to interact and be consistent with other regulatory bodies. Regional interaction is a part of this because markets and institutions operate in both a global and regional framework. While there is limited scope to create institutions to regulate matters that have fundamental global reach, there is a clear role for cooperation at the regional level to influence global developments and ensure that they meet regional needs.

These four papers cover much of the regional debate about how to ensure that unilateral, regional and multilateral approaches to crisis prevention and resolution are successful and complementary. They evoked considerable debate. Discussion mainly focused on regional financing facilities. Discussants identified three issues to be kept in mind in working out the details for a regional facility.

The first is having the right infrastructure in place to understand what is going on. Rajan's proposal for a regional CCL, for example, was read by some as implying that qualifying countries are more or less automatically entitled to financial support; that is, because they are fundamentally sound, any financing difficulty they face is basically an illiquidity problem, due, for example, to a self-fulfilling panic. This assumes that policymakers and markets can readily distinguish between liquidity difficulties and structural 'solvency' 
problems. The reality is that this is hard to do, especially because capital account crises tend to occur when there is some existing policy or financial weakness, ranging from a macroeconomic policy imbalance to a policy vulnerability such as an inappropriate exchange rate, poor transparency, weak governance or inadequate prudential regulation. Understanding what is going on is important to ensuring stability.

The risk of thinking that a crisis is due to liquidity when it is really due to structural imbalance is insufficient conditionality; the result is that the crisis will probably continue or re-emerge and that market confidence will be lost. The risk from thinking that a crisis is structural when in fact it is not is that the country is forced into more policy adjustment than is required. These risks are hard to balance.

The IMF's revealed preference would seem to be that it regards the first type of risk as more serious: too much conditionality is better than too little. The view that a country cannot have too much good policy has some obvious intuitive appeal. But there is a risk that pushing too hard on conditionality can unleash new political uncertainties and cause a program to unravel and confidence to be lost. The experience of Indonesia in 1997 and 1998 is a case in point.

For a regional facility, the main issue is whether it would bend in the opposite way to the IMF and be more likely to err in provide financing without sufficient conditionality, which would exacerbate the crisis. This is not a necessary outcome from a regional facility. Nor is it a likely outcome. Likely creditor countries in East Asia - for example, Japan, China, South Korea, Singapore and Australia - have no desire to put public funds at risk. The region has runs on the board in this respect. For example, in 1997 Japan declined requests from Thailand and South Korea for unconditional bilateral funding to boost their reserves.

A related issue for policymakers is how to coordinate regional and global initiatives. Supporters of a regional facility support a role for the IMF if the regional facility does not initially succeed. This basically makes the IMF the underwriter of the regional facility, but it is unlikely to be a role that the IMF itself will seek to play, all else given. If the regional round of financial stabilisation is completely independent of the global round, then coordination failures and greater uncertainty are more likely. Embedding the regional architecture in global processes, at least through clear dialogue and communication between the various channels, looks important.

Finally, there is a tendency to classify the spread of crises as being largely regional. This is true to a degree, but there are also many cases where financial crises spread to other regions. Global contagion was evident in 1998 with the spread of the Russian and Brazilian crises. For example, concern about Russian default in mid-1998 severely affected the currencies of Australia and South Africa at the time, well beyond the Russian region. Global risk management and portfolio repositioning can themselves be the vehicles for 
global contagion. A regional arrangement may still be an appropriate mechanism to provide financial support even in a cross-regional or global crisis. The rationale is marshalling regional resources to support regional partners.

\section{END PIECE}

East Asia is undergoing change and there is momentum to create a stronger regional economic and financial community. One dimension of the region's aspirations is the creation of strong robust mechanisms for financial governance, namely policy dialogue, surveillance and financial cooperation. We hope that this volume provides insight into the way this debate has emerged, what issues are facing the region, and how the debate might evolve in the future. 